\section{International Scientific Journal Theoretical \& Applied Science}

\author{
p-ISSN: 2308-4944 (print) e-ISSN: 2409-0085 (online) \\ Year: $2017 \quad$ Issue: $05 \quad$ Volume: 49
}

Published: $30.05 .2017 \quad$ http://T-Science.org
Alina Olegivna Dychko

Candidate of Technical Science, Associate Professor, Associate Professor of Engineering Ecology Department, National Technical University of Ukraine "Igor Sikorsky Kyiv Polytechnic Institute"

Igor Olegovych Opolinskyi

Master in Ecology and Environmental Protection, National Technical University of Ukraine "Igor Sikorsky

Kyiv Polytechnic Institute" opolinskyi@gmail.com

SECTION 11. Biology. Ecology. Veterinary.

\title{
ANALYSIS OF METHODS INCREASING THE PRODUCTIVITY OF BIOMASS ANAEROBIC PROCESSING TO BIOGAS
}

Abstract: The basic methods for improving performance processing of organic waste, which include: design solutions digester and auxiliary equipment; changing the composition of the substrate, additives to the substrate; adding additional substrate processing steps. Analyzed metanogenezisa technology increase productivity. The most promising method of increasing the productivity of methanogenesis is a method of substrate pre-treatment with an increase of biogas in output up to 4 times.

Key words: anaerobic processing of biomass, organic waste, biogas.

Language: Russian

Citation: Dychko AO, Opolinskyi IO (2017) ANALYSIS OF METHODS INCREASING THE PRODUCTIVITY OF BIOMASS ANAEROBIC PROCESSING TO BIOGAS. ISJ Theoretical \& Applied Science, 05 (49): 211-216.

Soi: http://s-o-i.org/1.1/TAS-05-49-32 Doi: crostef https://dx.doi.org/10.15863/TAS.2017.05.49.32

УДК 620.92

\section{АНАЛИЗ МЕТОДОВ ПОВЫШЕНИЯ ПРОИЗВОДИТЕЛЬНОСТИ АНАЭРОБНОЙ ПЕРЕРАБОТКИ БИОМАССЫ В БИОГАЗ}

Аннотация: Исследовано основные методы повышения производительности переработки органических отходов, $\kappa$ которым можно отнести: конструктивные решения метантенка и вспомогательного оборудования; изменения состава субстрата, добавки к субстрату; введение дополнительных этапов обработки субстрата. Проанализированы технологии повышения продуктивности метаногенезиса. Наиболее перспективными методом повышения продуктивности метаногенеза являются метод предварительной обработка субстрата с повышением выхода биогаза до 4 раз.

Ключевые слова: анаэробная обработка биомассы, органические отходы, биогаз.

\section{Introduction}

В настоящее время в мире в атмосферу, водоемы и почву ежегодно поступает более 50 млрд. тонн отходов энергетических, промышленных, сельскохозяйственных производств и коммунально-бытового сектора, в том числе от промышленных предприятий более 150 млн. тонн [1].

Общий объем твердых отходов в Украине составляет 10-11 млн. т в год. Свалками заняты 2600 га земель. В среднем в городах образовываются примерно 1 тонна на одного человека в год. Годовое количество образованных отходов в Украине за 2014 составляют около 354 млн. тонн. Из них переработанных или утилизированых только 112 млн. т, а остальные захоронены на свалках [2].

В тоже время, зависимость Украины от импортированных энергоносителей составляет 40\%. Согласно Энергетической стратегии Украины на период до 2030 года повышение энергоэффективности и уменьшения использования энергии является приоритетным направлением энергетической политики Украины. В соответствии с Национальным планом действий по возобновляемой энергетике на период до 2020 года общая мощность всех возобновляемых источников должна увеличиться более чем в 5,5 раза по сравнению со значением 2014 года. 
В нашей стране существуют значительные резервы вторичных ресурсов в том числе для получения биогаза [3]. Недостатками современных технологий утилизации отходов в анаэробных условиях в метантенках являются: невысокая эффективность процесс биотрансформации отходов в биогаз, низкий уровень метана в биогазе, большая продолжительность брожения, снижение выхода биогаза при лимитировании биогенных элементов в субстрате. Поэтому возникает необходимость в исследовании методов повышения производительности переработки органических отходов, уменьшения времени сбраживания и увеличения количества образованного биогаза с повышением доли метана в нем.

Прибыль от эксплуатации БГУ зависит от многих факторов, включая продажи «побочных» продуктов. Самую значительную прибавку к прибыли от продажи биометана можно получать от реализации жидких удобрений, поскольку это высоколиквидная продукция, пользующая постоянным спросом. Спрос на удобрения есть всегда, поскольку непреложным фактором функционирования аграрной биосистемы является баланс между внесением в почву и выносом из неё энергии в виде питательных веществ: внесение их должно быть не менее выноса.

Целью данной работе является анализ существующих перспективных направлений и технологий повышения эффективности анаэробной обработки биомассы.

\section{Materials and Methods}

По мере развития научно-технической мысли получение биогаза, как и любая другая технология, постепенно совершенствовалось в сторону большей эффективности. На основании изучения научно-технических источников можно выделить основные направления:

1. Конструктивные решения метантенка и вспомогательного оборудования

Основным направлением усовершенствования метантенков является повышение эффективности перемешивания субстрата - в силу того, что зависимость выхода биогаза от гомогенности субстрата крайне высока. В частности, существует предложение о модернизации гидравлической системы перемешивания [4], позволяющая значительно уменьшить объём так называемых «мёртвых зон», т.е. объёмов субстрата, которые при перемешивании с высокой вероятностью остаются не перемешанными. В целом данная технология позволяет значительно увеличить эффективность перемешивания субстрата.
При использовании модернизированной системы гидравлического перемешивания коэффициент полезного действия метантенка увеличивается на $8 \%$, а технологии в целом на $10 \%$ [4].

Другим направлением является стабилизация температурного режима в метантенке и повышение температуры в нём. Как известно, существует три основных температурных режима метаногенеза психофильный, мезофильный и термофильный, из которых термофильный является наиболее эффективным [5]. В то же время при термофильном режиме система наиболее энергоёмка и чувствительна к колебаниям температуры (что в первую очередь выражается в наиболее узком температурном диапазоне). Таким образом достигается цель с минимумом энергетических и финансовых затрат довести температуру до мезофильного диапазона, защитив метантенк от губительных температурных колебаний.

Также к категории конструктивных решений можно отнести мешалки с переменным расстоянием между мешалкой и валом. Так, с увеличением плотности и вязкости культивационной среды лопасти мешалок отводят от вала, окружная скорость лопастей возрастает, и таким образом, достигается более интенсивная турбулизация культивационной среды с аэрирующим газом, а поярусное распределение мешалок на валу привода должно обеспечить равномерность такого перемешивания [6].

Сравнительно новой является идея солнечного соляного пруда как конструктивного элемента биогазовой установки. Соляной пруд действует, с одной стороны, как теплоизолятор, с другой - как объект, пропускающий солнечное излучение. При выработке биогаза использование солнечной энергии для подогрева субстрата в большом метантенке позволит летом и осенью применять термофильный режим ферментации, в этом случае при том же объеме метантенка выход биогаза увеличится в $1,5-2$ раза. [7].

2. Изменения состава субстрата, для сбраживания

Современные технологии позволяют перерабатывать в биогаз практически любые виды органического сырья, однако наиболее эффективно использование биогазовых технологий для переработки отходов животноводческих и птицеводческих ферм, предприятий агропромышленного комплекса и сточных вод, так как они характеризуются постоянством потока отходов во времени и простотой их сбора. Поскольку сырьем для получения биогаза может служить широкий спектр органических отходов, на многих 
существующих биогазовых установках используется добавка к обрабатываемым отходам.

Активного обмена веществ и высокой скорости биохимических обменных процессов можно достигнуть, если поддерживать и непрерывно обновлять максимально возможную величину граничных поверхностей между твердой и жидкой фазами. Поэтому твердые материалы, в особенности растительного происхождения, должны быть предварительно подготовлены с помощью режущих или разрывающих устройств, чтобы в результате эффективного механического воздействия получить частицы возможно меньшего размера. Доля взвешенных в жидкости твердых частиц в значительной мере зависит от технических средств, которые используются для получения тщательного перемешивания, гидравлического транспортирования субстрата и отделения газа.

Для увеличения соотношения метаногенных бактерий в микрофлоре биореактора используют биостимулятор [8]. Содержание метана в биогазе может доходить до $86 \%$, самое большое в сточных водах, где в качестве основного субстрата - крахмаль, а содержание метана может быть выше 75\%. Содержание метана в биогазе в контрольной группе в целом 60-65\%.

Фитомасса амаранта сокращает лаг-фазу газообразования в 4 раза - значительно повышая процент метана в образуемом биогазе. Выявлено влияние амаранта на ацидогенную фазу сбраживания [9]. Максимальное содержание метана в биогазе достигнуто при сбраживании отходов сточных вод с добавлением 24\% амарантового жома составило $83 \%$.

При введении биостимуляторов [10] в биохимический процесс даже в незначительных количествах повышается скорость роста бактерий и интенсивность анаэробного сбраживания. Это приводит к снижению времени процесса, что, в свою очередь, может существенно снизить капитальные и эксплуатационные затраты. Получены хорошие результаты при использовании для этих целей «мелафена» синтетического стимулятора развития растений, являющегося меламиновой солью бис(оксиметил)фосфиновой кислоты [11].

Композиция таких соединений, как типа BIOSTIM-SBCH 4 , способствует интенсификации процесса анаэробного сбраживания органического субстрата барды, и как следствие, повышению общего выхода биогаза, а в ряде случаев - и содержания в нём метана. Их использование в 3-4 раза повышает скорость выделения газа и производительность процесса метаногенеза. Одновременно с этим, их введение в метаногенный процесс приводит к увеличению доли метана в составе биогаза с 65-70\% до 90$95 \%$. Благодаря антиоксидантной, антигипоксантной и антимутагенной активности, они стабилизируют клеточные мембраны микроорганизмов, повышают их устойчивость к повреждению в условиях недостатка кислорода и, одновременно с этим, препятствует перекисному окислению липидов.

\section{3. Введение дополнительных этапов} обработки субстрата

Практически все биогазовые установки работают с субстратом, предварительно доведённым до необходимого уровня влажности и гомогенности.

Согласно способу [12], исходный субстрат последовательно проходит стадии аэробной предварительной обработки и анаэробной переработки в эффлюент и биогаз. Эффлюент подвергается механическому разделению с получением пригодной для агротехнического использования твердой фракции (кека) и жидкой фракции. Жидкая фракция, характеризующаяся высокими значениями биологического потребления кислорода (не менее 3-4 г/л) и взвешенных веществ (до 8 г/л), после отстаивания подвергается аэробной обработке, с утилизацией (до 30\%) кислорода, не прореагировавшего с биомассой на стадии предварительной аэробной обработки субстрата. Осадок подвергается повторному механическому разделению [12].

В результате снижается степень аэробного распада исходного органического вещества, необходимого для достижения нагрева исходного субстрата, и возрастает выход биогаза на последующей анаэробной стадии обработки. Избыточный активный ил, образовавшийся на замыкающей аэробной стадии, после уплотнения подается на анаэробную обработку и также перерабатывается в биогаз и эффлюент. Вода из аэротенка после доочистки и обеззараживания в типовых установках может быть использована в технических целях или сброшена в водоем [12].

Сравнительный анализ методов повышения продуктивности метаногенеза с указанием их основных достоинств и недостатков, а также ожидаемая доля повышения производительности образования биогаза в процентах представлен в табл.1. 


\begin{tabular}{|c|c|c|c|c|c|c|}
\hline Impact Factor: & $\begin{array}{l}\text { ISRA (India) } \\
\text { ISI (Dubai, UAF } \\
\text { GIF (Australia) } \\
\text { JIF }\end{array}$ & $\begin{array}{l}=1.344 \\
=0.829 \\
=0.564 \\
=1.500\end{array}$ & $\begin{array}{l}\text { SIS (USA) } \\
\text { PИНЦ (Russia) } \\
\text { ESJI (KZ) } \\
\text { SJIF (Morocco) }\end{array}$ & $\begin{array}{l}=0.912 \\
=0.234 \\
=3.860 \\
=\mathbf{2 . 0 3 1}\end{array}$ & $\begin{array}{l}\text { ICV (Poland) } \\
\text { PIF (India) } \\
\text { IBI (India) }\end{array}$ & $\begin{array}{l}=6.630 \\
=1.940 \\
=4.260\end{array}$ \\
\hline
\end{tabular}

Таблица 1

Методы повышения продуктивности переработки органических отходов

\begin{tabular}{|c|c|c|c|}
\hline $\begin{array}{l}\text { Наименование } \\
\text { метода }\end{array}$ & Краткое описание & Основные достоинства / недостатки & \begin{tabular}{|lr} 
Ожидаемая \\
повышения \\
производительности, \%
\end{tabular} \\
\hline $\begin{array}{l}\text { Перемешивание } \\
\text { субстрата }\end{array}$ & $\begin{array}{lr}\text { Уменьшение } & \text { количества } \\
\text { «мертвых } & \text { зон», } \\
\text { стабилизация } & \\
\text { температурного режима }\end{array}$ & $\begin{array}{l}\text { Дешевизна / } \\
\text { Проблематичность } \quad \text { внедрение } \\
\text { действующие установки }\end{array}$ & $8-10 \%$ \\
\hline $\begin{array}{l}\text { Температурный } \\
\text { режим }\end{array}$ & \begin{tabular}{|l|} 
Стабилизация \\
(повышение \\
снижение) температуры \\
субстрата \\
\end{tabular} & \begin{tabular}{|l|} 
Повышения продуктивности выхода \\
биогаза / \\
Повышение энергозатрат, дороговизна
\end{tabular} & $10-15 \%$ \\
\hline $\begin{array}{l}\text { Конструкция } \\
\text { метантенка }\end{array}$ & $\begin{array}{l}\text { Изменение } \\
\text { размеров и конструкции } \\
\text { метантенка }\end{array}$ & $\begin{array}{l}\text { Повышение продуктивности / } \\
\text { Проблематичность переоборудования } \\
\text { действующих установок }\end{array}$ & $10-12 \%$ \\
\hline $\begin{array}{l}\text { Предварительная } \\
\text { подготовка } \\
\text { субстрата }\end{array}$ & $\begin{array}{|ll|}\text { Устройства } & \text { дробления, } \\
\text { сепарации, } & \text { резки для } \\
\text { увеличения } & \\
\text { однородности субстрата } \\
\end{array}$ & \begin{tabular}{|l|} 
Возможность \\
действующие станции / \\
Повышение энергозатрат, дороговизна
\end{tabular} & $5-8 \%$ \\
\hline $\begin{array}{l}\text { Добавки и } \\
\text { биостимуляторы }\end{array}$ & \begin{tabular}{|l|} 
Добавление веществ, \\
обеспечивающих \\
жизнедеятельность \\
микроорганизмов \\
\end{tabular} & \begin{tabular}{|l} 
Возможность \\
действующие станциновки \\
доли метана в биогазе / \\
Повышение энергозатрат \\
\end{tabular} & $15-30 \%$ \\
\hline $\begin{array}{l}\text { Предварительная } \\
\text { обработка } \\
\text { субстрата }\end{array}$ & $\begin{array}{l}\text { Включает химическую, } \\
\text { биологическую, физико- } \\
\text { химическую } \\
\text { всего обработку } \\
\text { субстрата }\end{array}$ & 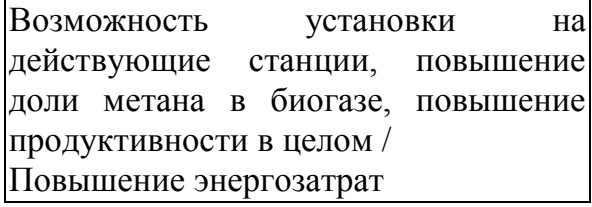 & $60-80 \%$ \\
\hline $\begin{array}{l}\text { Дополнительные } \\
\text { стадии } \\
\text { сбраживания }\end{array}$ & $\mid$\begin{tabular}{|l} 
Два и и \\
метантенка
\end{tabular} & \begin{tabular}{|lr} 
Повышение качества & переработки \\
субстрата, & повышение \\
продуктивности/ & \\
Дороговизна, & проблематичность \\
переоборудования & действующих \\
установок
\end{tabular} & $20-30 \%$ \\
\hline
\end{tabular}

Наиболее перспективными методами являются: 1. Конструктивные решения метантенка и вспомогательного оборудования;
2. Изменения состава субстрата, присадки и добавки к нему; 3. Введение дополнительных этапов обработки субстрата (Рис. 1). 


\begin{tabular}{l|lrl|l|ll} 
& ISRA (India) & $=\mathbf{1 . 3 4 4}$ & SIS (USA) & $=\mathbf{0 . 9 1 2}$ & ICV (Poland) & $=\mathbf{6 . 6 3 0}$ \\
Impact Factor: & ISI (Dubai, UAE) $=\mathbf{0 . 8 2 9}$ & PUHU (Russia) $=\mathbf{0 . 2 3 4}$ & PIF (India) & $=\mathbf{1 . 9 4 0}$ \\
& GIF (Australia) & $\mathbf{0 . 5 6 4}$ & ESJI (KZ) & $=\mathbf{3 . 8 6 0}$ & IBI (India) & $\mathbf{4 . 2 6 0}$
\end{tabular}

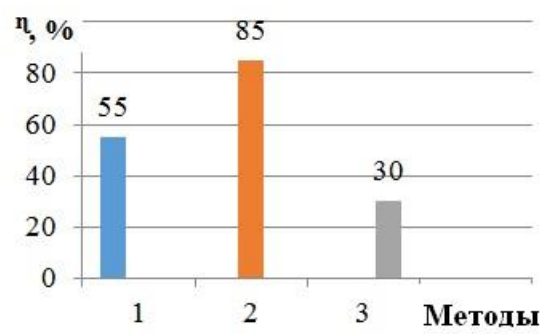

Рисунок 1 - Сравнение методов повышения продуктивности метаногенеза:

1-Конструктивные решения метантенка и вспомогательного оборудования;

2-Изменения состава субстрата, присадки и добавки к нему;

3-Введение дополнительных этапов обработки субстрата;

ๆ - повышение продуктивности, \%;

Максимальный выход биогаза - до $85 \%$ позволяет достичь метод предварительной обработки субстрата. Так, химическая обработка биомассы перекисью водорода позволить расщепить сложные органические соединения биомассы, ускорить процесс биотрансформации и обеспечит микроорганизмы биомассы метантенка биогенными элементами, необходимые для высокой эффективности метаногенеза. На основе экспериментальных исследований нами было установлено, что при применении перекиси водорода для деструкции части биомассы, которая подавалась после первой стадии метаного брожения на вторую стадию в метантенк в количестве $15 \%$ от общего объема субстрата, производительность образования биогаза увеличивается до 4-х раз [13-15].

\section{Выводы}

К основным методам повышения эффективности метаногенеза относят: конструктивные решения метантенка и сопутствующего оборудования; стимуляторы изменения состава субстрата; введение дополнительных этапов его обработки перед непосредственно помещением в метантенк.

Наиболее перспективными являются методы предварительнойхимической обработки субстрата с повышением продуктивности метаногенеза до $80 \%$.

Последующие исследования целесообразно направить на определение оптимального соотношением рассмотренных технологий повышения продуктивности переработки органических отходов для интенсификации выхода биогаза.

\section{References:}

1. Vasyukova GT (2009) Ekologiya. Kyiv. Kondor, p. 524.

2. (2015) Statystychnyj shhorichnyk Ukrayiny za 2014 rik. Derzhavna sluzhba statystyky Ukrayiny. Available: https://ukrstat.org/uk/druk/publicat/kat_u/publ1 u.htm (Accessed: 10.05.17).

3. Ratushnyak GS, Dzhedzhula VV, Anoxina KV (2010) Energozberigayuchi vidnovlyuvalni dzherela teplopostachannya. Vinnycya: VNTU, p. 170

4. Trakhunova IA (2001) Povysheniye effektivnosti anaerobnoy pererabotki organicheskikh otkhodov $\mathrm{v}$ metantenke $\mathrm{s}$ gidravlicheskim peremeshivaniyem na osnove chislennogo eksperimenta: dis. kand. tekhn. Nauk. Kazan. p. 137.

5. Osadchiy GB (2012) Individualnaya biogazovaya ustanovka. Available: 


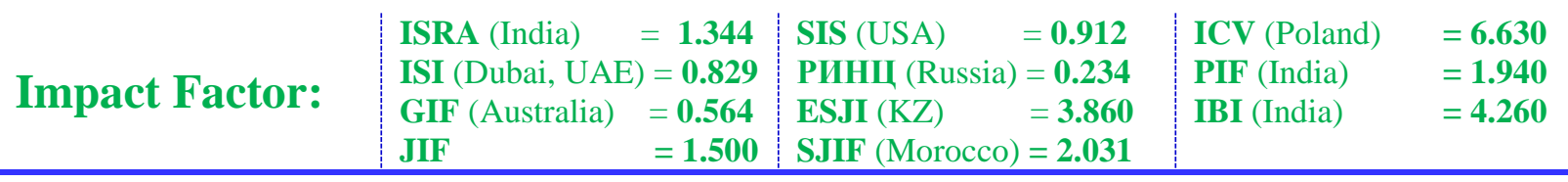

http://renewable.com.ua/bio/84-individualnajabiogazovaja-ustanovka.html (Accessed: 10.05.17).

6. Redikultsev YV, Kudryashov VK, Orlov DV (1995) Patent 2031113 RF. Bioreaktor.

7. Semenov AV (2006) Patent 2272392 RF. Bioenergeticheskaya ustanovka.

8. Xue Rong Zang Lihua (2013) Patent $103642846 \mathrm{CN}$. Accelerant for increasing methanogenesis ratio of methane bacteria.

9. Kovalev VV, Unguryanu DV, Kovaleva OV (2012) Teoreticheskiye i prakticheskiye aspekty sovershenstvovaniya protsessov Problemy regionalnoy energetiki. p. 102-114.

10. Barskiy EL, Shandiyeva IO, Savanina YV (2011) Effekt melafena na razvitiye kultur tsianobakteriy i zelenykh mikrovodorosley $\mathrm{v}$ stressovykh usloviyakh. Vestnik Moskovskogo gosudarstvennogo universiteta. p. 15-20.

11. Kovalev DA, Kovalev AA, Kamaydanov EN (2011) Patent 2504520 RF. Sposob biologicheskoy obrabotki kontsentrirovannykh organicheskikh substratov $\mathrm{s}$ polucheniyem

Available: (Accessed: 10.05.2017). et al. udobreniy. gazoobraznogo energonositelya i tekhnicheskoy vody i ustroystvo dlya ego realizatsii.

12. Lu Yongzhu (2015) Patent 104498341 CN. Biogas production method for dragon type super-effective biogas fermentation system.

13. Dychko AO, Yevtyeyeva LI, Opolinskiy IO (2015) The intensification of the process of transformation of biomass into bioenergy biogas. Managing the development of complex systems. № 22 (1). p. 193-198.

14. Vorobyov VD, Dichko AO, Opolinskiy IO (2016) Pidvishchennya efektivnosti biotransformatsiï ekologichno nebezpechnikh polyutantiv stichnikh vod u biogaz Visnik Natsionalnogo tekhnichnogo universitetu Ukraïni «Kiïvskiy politekhnichniy institut». Seriya «Girnitstvo». №30. p.153-159.

15. Dychko AO, Yevtyeyeva LI, Opolinskiy IO (2016) Waste and wastewater treatment bottleneck management. Ekologichna bezpeka. №21 (1). p.123-126. 